THE

\title{
Journal
}

\section{$\boldsymbol{\Theta F}$ \\ Nervous and Mental Disease}

\section{Original : Frticles}

A CASE OF EPILEPSY ASSOCIATED WITH ACROMEGALY.

By William T. Shanahan, M.D., -

FIRST ASSISTANT PHYSICIAN, THE CRAIG COIONY FOR EPLLETICS, SONYEA, N. Y.

As the number of cases of acromegaly associated with epilepsy reported has been so small, I wish to add the following one which recently came under my observation.

L. S., thirty-one years of age, married, housekeeper. Father living and well. Mother died at age of twenty-four years, two weeks after birth of patient, assigned cause being some complication of confinement. History of grandparents negative as is also that of remainder of family. Patient was a puny infant, weighing but three pounds at birth. Had swollen cervical glands during infancy and diphtheria at seven years. Married at twenty years of age. About two years later first symptoms of acromegaly appeared. At age of twenty-six years she had her first epileptic seizure. This seizure was apparently grand mal in type. Seizures then varied in frequency. from one in two days to one in three weeks. No aura. She would not know she had had a seizure but for her lacerated tongue. Left side first involved in some seizures.

When admitted to the Colony she was well-nourished, weight being 168 pounds. Temperature, pulse, and respiration normal. Occipito-frontal circumference of head $54 \mathrm{~cm}$. General massiveness of face, especially nose and inferior maxilla. Circumference neck $36 \mathrm{~cm}$. Marked spacing of teeth in inferior maxilla. Tonsils moderately enlarged. Some macroglossia, patient complaining that speech is thick because of this condition. Prominent transverse rugæ on anterior portion of hard palate. Fingers are very broad. She does not know size of gloves formerly worn, but states that she is now unable to place wedding-ring on little finger of left hand, whereas said ring was at first too large for ring finger of that hand. She formerly wore No. $3 \frac{1}{2}$ shoes, but 
now wears the largest she can buy; she wore No. 6 when admitted. Very marked kyphosis in cervico-dorsal region, slight scoliosis also present. Circumference of chest one meter.

Skin is of a brownish tinge, especially on face and neck. No flushing, cyanosis or change in hair or nails, except latter are somewhat broadened. Mucous membranes slightly pale. Blood count and percentage of hemoglobin normal.

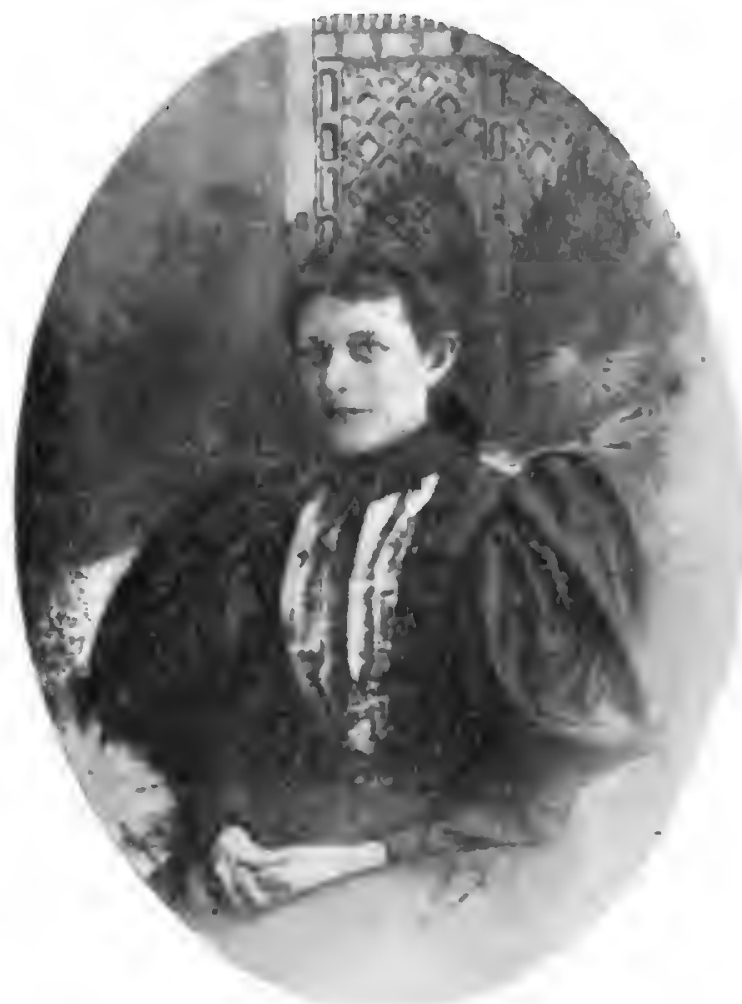

Fig. I. Taken two years before onset of acromegaly.

Slight enlargement of postcervical glands, no tibial nodes or other evidence of syphilis. Thyroid not palpable.

Moderate exophthalmos present. Pupils normal. Patient states that at times she is much annoyed by an involuntary twitching of eyelids. Examination of fundus shows no abnormality. Patient can readily read ordinary newspaper print. No hemianopsia, strabismus or nystagmus, except slight lateral when she looks to extreme right or left. She has never worn glasses. 
At times chring the last few months she has had a buzzing sound in ears, especially right. She says it resembles the sound of machinery. Hearing apparently normal as tested with voice and watch. Taste normal; smell somewhat impaired on both sides.

Breathing is mostly costal in type. Diminished expansion,

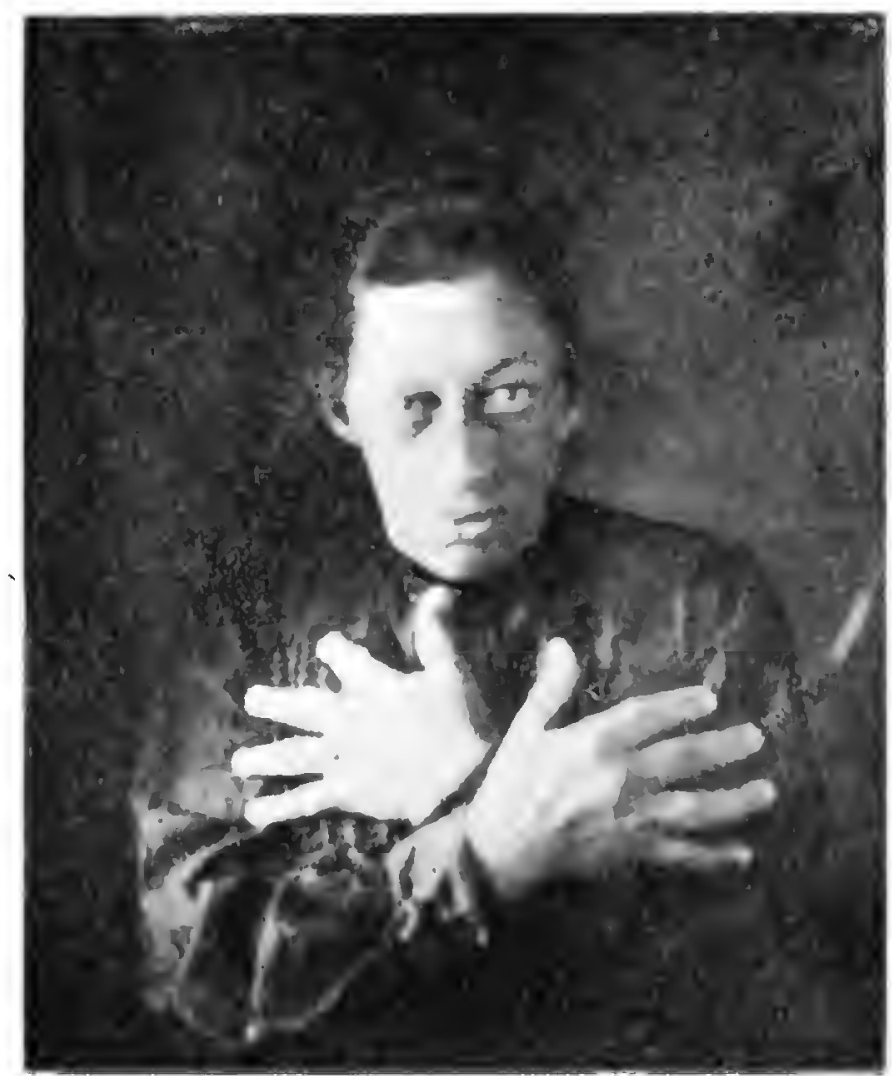

Fig. 2. Taken shortly after admission to the colony in 1906.

otherwise respiration is normal. No dillness over site of thymus.

Cardiac dullness slightly increased to left of mid-clavicular line. Blood pressure normal. Some accentuation of second pulmonic sound.

Tongue coated, some gingivitis in inferior maxilla. No increase in appetite or thirst. Bowels usually constipated. Examination of abdomen negative.

Urine normal; no polyuria, but as patient sometimes 
urinates involuntarily, it is difficult to measure amount accurately.

Breasts atrophied; uterus very small. Menstruation began at age of twelve years. and was regular until onset of acromegaly, at which time it ceased, and has not reappeared.

Several years ago she had severe occipital headache, also a bursting sensation in eyeballs. At present, and for some time past, has had no headlache. Indefinite history of having had vertigo at about the same time headaches occurred.

Voice moderately hoarse.

Cutaneous sensibility - normal; considerable increase in perspiration with some fetid odor accompanying it. Reflexes moderately active. No paralysis of any part. Musculature good; dynamometer registers more than the average for her sex. Patient herself claims she is not as strong as formerly. Co-ordination and sense of position normal. She has difficulty in assuming an erect posture because she says it "hurts her backbone." Gait is normal except for slight awkivardness.

Mental condition is good for one in her station in life. Can write without difficulty.

Since admission she has had frequent petit mal seizures, which begin in left hand as if she were trying to approximate finger tips. Moderate dilatation of pupils, involuntary urination, marked automatism. Duration of seizure about one minute. Patient has no recollection of having had seizures. No distinctive convulsive movements observed during these seizures. A few grand mal seizures have occurred, but under such circumstances as to preclucle their being satisfactorily observed.

A somewhat extended review of the literature on the subject brings to light the following cases, in which a definite history of convtlsions accompanies that of acromegaly.

Grinker $^{1}$ reports a man of 45 years of age, who, eight years before, had some "psychic traumatism." Had sensations as in petit mal seizures, then after a year somnolence and marked weakness. Then screaming attacks with trembling of the legs and crying. Two years later is said to have had his first epileptic attack. He now had marked enlargement of the nose, eyebrows, inferior maxilla, hands, and feet. No disorder of the eye muscles or of the optic nerves. Larynx not enlarged. No other nervous abnormalities. Mental weakness present. This case was said to belong to the chronic form, which lasts from eight to thirty years.

Farnarier $^{2}$ reports a typical case of acromegaly associated 
with epilepsy and a condition approaching dementia.

Hinsdale $^{3}$ quotes from Raymond and Sonques, who describe a case of acromegaly, of many years' standing, in a man of fifty-four years, who in the last three years developed Jacksonian epilepsy.

Hinsdale also quotes from Marinesco, who describes a woman aged thirty-two years who had epilepsy beginning at twenty-two years, the attacks occurring three or four times a week. At the age of twenty-five years she had an attack of giddiness in which she fell from a second floor. Six months later she noticed that her feet were enlarged, and later her hands, face, and abdomen. Menses ceased. Strabismus, polyuria. and weakness supervened. Sensibility preserved in all forms except vision. Examination revealed bitemporal hemianopsia. Glycosuria present.

A. Napier* reports a case of acromegaly in a woman, with onset at twenty-five years. Later she had an epileptic seizure with albuminuria.

Hutchings ${ }^{5}$ reports a man aged forty-four years, who had epilepsy since puberty. Acromegaly at thirty-six years. Dementia present.

In the discussion ${ }^{5}$ is mentioned a case of acromegaly with epilepsy in a young man of twenty-eight years.

Oestreich and Slavyk ${ }^{6}$-acromegaly in a boy of four years. Convulsions present. Autopsy showed cystic psammo-sarcoma of pineal gland. Pituitary normal.

Jollyi mentions a case of acromegaly having petit mal seizures.

$\mathrm{Gatt}^{\mathrm{s}}$ reports a woman aged fifty-six years who had acromegaly for more than ten years. This was preceded by insomnia and headache for several years. Two years before report she had convulsive attacks. Autopsy revealed sarco$\mathrm{ma}$ in the sella turcica and adjoining bone. Colloid cysts in thyroid.

De Blasio" reports an acromegalic skull in an epileptic who had syphilic hepatitis.

Graves ${ }^{10}$ reports a case of myoclonus epilepsy which developed acromegaly.

M. F. Moutier ${ }^{11}$ reports a man aged 36 years. At twentythree years of age, during military service, he had measles and 
typhoid, also some indefinite genital trouble. Since then he has become fat, lost strength, and has had violent headaches. His military service was interrupted by blindncss of the left eye, preceded by severe pain in eye and marked vomiting. It could not be ascertained when the acromegalic deformities commenced. The patient remembered that when seven or eight years of age he attracted attention because of his large hands and feet. Now has characteristic appearance of acromegaly. Indefinite lancinating pains in legs and jaw. A se. vere parieto-frontal headache, which was unrelieved by remedies. Complete left optic atrophy. Mental condition failed considerably since 1893 , especially memory for recent erents. Became morose.

The convulsive phenomena appeared first in 190r. These appeared every day for eighteen months. then became less frequent, but have again become very frequent, occurring two or three times daily. At present psychic equivalents appear often. No aura. Convulsive seizures are apparently grand mal in type. Psychic equivalents were first observed in 1905 He had shorf spells of vertigo before this time.

Moutier says epileptiform crises are more frequently observed in this class of cases than are the mental changes. During the intervals between seizures the patient is intelligent. He is inclined to believe that the canse of the condition is some cerebral tumor, hypophyseal or otherwise.

He states that these phenomena of automatism are exceptional and does not see how to indicate as analogous any but the case of Devic and Gauthier, in which there was a glioma of the frontal lobes and left sphenoidal lobes. Their patient, a woman of fifty-two years of age, had presented a slight tendency toward ambulatory automatism.

The question naturally arises as to how many of these cases have been merely symptomatic Jacksonian types and how many had typical grand mal or petit mal seizures, associated with mental symptoms characteristic of epilepsy. It would appear that some of the cases had epileptiform convulsions accompanying brain tumor.

The weight of opinion seems to indicate that acromegaly is due to an affection of the essential substance of the pituitary gland. This may be caused by some malignant growth, viz., 
sarcoma, which either involves the gland substance or else causes atrophy or change in function by pressure. Again it may be caused by a benign growth which slowly brings about changes in the gland.

A large number of cases of tumor of the pituitary gland and surrounding structures have been reported in which there have been no symptoms of acromegaly. In these cases, it was deemed very probable that the pituitary structure was not involved or at least only partially, as in many of these cases there is no mention made of a careful microscopical examination of the pituitary body.

Kollarits thinks that tumor of the hypophysis is not the fundamental cause of acromcgaly, but rather one of the symptoms, as he reports 53 cases in which there was tumor of the hypophysis without acromegaly.

Many of these hypophyseal tumors are thought to originate in the infundibulum.

F. Farnarier thinks that degenerative states are favorable for the development of acromegaly and that certain changes in the hypophysis react on the nervous system already in a state of instability by the hereditary influences.

Boettiger considers a toxemia as the cause of acromegaly. The pituitary gland is thought by some authors to have an important trophic influence on the central nervous system. Interference with this function or complete ablation of the gland would bring about a state of toxemia, and so convulsions of various types. In order that convulsions may occur it seems reasonable to think that there must necessarily be a lack of stability in the cortical cells in such acromegalics. This would lead one to consider the pituitary changes as one of the many exciting causes of convulsions or other symiptoms of epilepsy.

If a tumor of the pituitary is present, it is but reasonable to believe that the epileptoid symptoms may be produced by direct pressure on the cortical substance, by increase in the size of the tumor, or else by general increased intracranial tension and so bring about convulsive movements.

Various nervous phenomena may be due to the defective nutrition or the accumulation of toxic substances in the body. Brooks claims that if there is no glycosuria or hemianopsia 
it is questionable as to the involvement of the pituitary body.

Heersman's theory is that the hypophysis neutralizes through its products in the blood the secretion of other blood glands. It regulates the vascular system and hinders the growth of bone. Through lack of this secretion acromegaly develops. This is the restult of a tumor of the pituitary or of a secondary alteration through a chronic alteration of the blood.

Cushing states as follows: "A disturbance of the menstrual function may be one of the earliest symptoms of some intracranial tumors. Growths in most diverse situations, or indeed an increase of intracranial tension has been known to affect the regularity or even completely interrupt for long periods, previously normal catamenia. These cases may be divided into two groups: one, those in which amenorrhea accompanies tumors of the hypophysis or tumors affecting the gland by direct compression. The other, those in which the menstrual disturbance is a symptom of tumors situated elsewhere.

The occurrence of diabetes, mental disorders, epilepsy, etc., with acromegaly may be the result of a perverted pituitary secretion on unstable tissues, or stuch a secretion or an entire lack of secretion may produce this instability and so allow other toxins to bring about such conditions.

The case now under observation will be followed carefully so as to ascertain further exe changes and if death occur, to procure an autopsy.

\section{REFERENCES.}

${ }^{1}$ Acromegaly with Epilepsy. Grinker. Chicago Medical Examiner, December, I903, Abstracted in Neurol. Ccntrlblatt, I904.

${ }^{2}$ Abstract in Journal Nervous AND Mental DiSEASE, Vol. 27, p. 456. Acromegaly and Mental Degeneracy.

Acromegaly-Syringomyelia. Guy Hinsdale.

"Glasgow Med. Journal, Vol. 49. Jahresbericht, 1898 .

${ }^{\circ A}$ rchives of Neurology and Psychopathology, Vol. I, No. 4.

'Jahresbericht Neurologie und Psychiatrie, I899.

'Idem, I899.

${ }^{\text {ITdem, Igoz. }}$

'Idem, I903-

${ }^{10}$ Idem, I904.

${ }^{11}$ Rev. Nel1rologique, Nov. 30. 1906. J. Kollarits, Abstract in American Medicine. Nov. Ir, I905. British Medical Journal, I899, Vol. I, p. 850. Harvey Cushing. Sexual Infantilism with Optic Atrophy in Cases of Tumor Affecting the Hypophysis Cerebri. Journal Nervous and Mental DISEASE. November. Ig06. Burr and Riesman. Idem, January, I899. Sidney Kul?. Idem. Vol. 28. p. 419. Idem, Vol. 31, p. 54. Abstract of Article by Lannois and Roy. Acromegaly and Diabetic Gout. $H$. Brooks, Árchives of Neurology and Psychopathology, Vol. I. 